\title{
Long-term effects of biogeophysical and biogeochemical interactions between terrestrial biosphere and climate under anthropogenic climate change
}

\author{
G. Schurgers ${ }^{\mathrm{a}, *}$, U. Mikolajewicz $^{\mathrm{a}}$, M. Gröger ${ }^{\mathrm{a}, 1}$, E. Maier-Reimer ${ }^{\mathrm{a}}$, M. Vizcaíno ${ }^{\mathrm{a}, 2}$, A. Winguth ${ }^{\mathrm{b}, 3}$ \\ a Max Planck Institute for Meteorology, Bundesstrasse 53, 20146 Hamburg, Germany \\ ${ }^{\mathrm{b}}$ Center for Climatic Research, Department of Atmospheric and Oceanic Sciences, 1225 W. Dayton St, Madison, USA
}

\section{A R T I C L E I N F O}

Article history:

Accepted 13 January 2008

Available online 13 September 2008

Keywords:

Earth system modelling

biogeochemistry

biogeophysics

global warming

\begin{abstract}
A B S T R A C T
A complex earth system model, simulating atmosphere and ocean dynamics, marine biogeochemistry, terrestrial vegetation and ice sheets, was used to study feedbacks between the terrestrial biosphere and climate with a set of long-term climate change ensemble experiments. $\mathrm{CO}_{2}$ emissions were assigned according to historical data and the IPCC SRES scenarios B1, A1B and A2, followed by an exponential decay of the emissions for the period 2100-3000. The experiments give a reasonable reconstruction of the measured $\mathrm{CO}_{2}$ concentrations between 1750 and 2000. Maximum atmospheric $\mathrm{CO}_{2}$ concentrations of $520 \mathrm{ppm}$ (B1), $860 \mathrm{ppm}$ (A1B) and $1680 \mathrm{ppm}$ (A2) were reached between 2200 and 2500. Additional experiments were performed with $\mathrm{CO}_{2}$ emissions and suppressed climate change, as well as an experiment with a prescribed land surface. The experiments were repeated with the vegetation model driven offline, to investigate the effects of climate and $\mathrm{CO}_{2}$ changes separately. The biogeochemical and biogeophysical interactions between terrestrial biosphere and atmosphere were quantified and compared.

A decrease of albedo at high latitudes was the most important biogeophysical change. For the A2 scenario experiment, it causes an additional temperature increase of 1 to $2 \mathrm{~K}$ for some high latitude regions by the year 3000, but the changes are minor compared to the heating due to $\mathrm{CO}_{2}$ increase.

The terrestrial biosphere takes up between 15 and 30\% of the $\mathrm{CO}_{2}$ emissions, depending on the scenario and the period considered. The carbon is stored in the tropics and subtropics, where carbon is stored fast, and in the high latitudes, where carbon storage, partly due to forest expansion, is much slower. By the year 3000, the storage of terrestrial carbon results in a decrease of atmospheric $\mathrm{CO}_{2}$ concentration of $400 \mathrm{ppm}$, which in turn decreases the global temperature increase by $0.4 \mathrm{~K}$.
\end{abstract}

(c) 2008 Elsevier B.V. All rights reserved.

\section{Introduction}

Since the beginning of continuous measurements of the atmospheric $\mathrm{CO}_{2}$ concentration at the end of the 1950s (Keeling, 1960), the $\mathrm{CO}_{2}$ concentration has been known to rise, currently with a rate of about $1.5 \mathrm{ppm} \mathrm{y}^{-1}$ (Houghton et al., 2001). This increase, combined with the awareness of the fact that $\mathrm{CO}_{2}$ is a greenhouse gas (Arrhenius, 1896), has given rise to numerous modelling studies trying to describe the uptake of carbon by the terrestrial biosphere and the ocean for the last centuries, and trying to predict the uptake for the centuries to come.

\footnotetext{
* Corresponding author. Now at: Department of Physical Geography and Ecosystems Analysis, Lund University, Sölvegatan 12, 22362 Lund, Sweden. Tel.: +46 46222 8691; fax: +46 462220321 .

E-mail address: guy.schurgers@nateko.lu.se (G. Schurgers).

1 Now at: Mainz Academy of Sciences, Humanities, and Literature, IFM-GEOMAR, Wischhofstrasse 1-3, 24148 Kiel, Germany.

2 Now at: Department of Geography, University of California at Berkeley, 531 McCone Hall, Berkeley, CA 94720-4740, USA

${ }^{3}$ Now at: Department of Earth and Environmental Sciences, University of Texas at Arlington, Box 19049, Arlington, TX 76019-0049, USA.
}

Early studies (e.g. Björkström, 1979; Goudriaan and Ketner, 1984) focused on the role of the terrestrial biosphere as a part of the carbon cycle and as a potential sink for the emitted $\mathrm{CO}_{2}$. In these studies interactions of the terrestrial biosphere with the global carbon cycle were investigated, but the effects of climate change were not taken into account. Later, distinct models of the ocean and the terrestrial biosphere were developed, driven with climate data from observations or from climate modelling studies. Many different models for the terrestrial biosphere exist, ranging from simple descriptions of the most important processes (e.g. Brovkin et al., 1997) to an explicit representation of the biogeographical distribution of plant types and detailed process descriptions (e.g. Foley et al., 1996; Sitch et al., 2003).

The biogeophysical effects of climate change due to changes in the $\mathrm{CO}_{2}$ concentration were studied with climate models. Changes in the vegetation that were studied in relation to future climate change or as a consequence of other anthropogenic disturbances include climateinduced shifts of the boreal forest zone (Otterman et al., 1984; Brovkin et al., 2003), deforestation in the high latitudes of the northern hemisphere (Bonan et al., 1992; Douville and Royer, 1997) as well as in the tropics (Dickinson and Henderson-Sellers, 1988; Shukla et al., 1990), and natural or anthropogenic changes in the vegetation cover of the 
North African monsoon region (Charney, 1975; Wang and Eltahir, 2000; Claussen et al., 2003). These regions are either heavily influenced by mankind, or are likely to show an amplification of the primary forcing due to positive feedbacks between the land surface and the climate.

Coupled climate-vegetation models were used to study climate and vegetation as a coupled system, thereby taking both biogeochemical and biogeophysical effects into account. Experiments with intermediate complexity models were performed using future $\mathrm{CO}_{2}$ scenarios (Petoukhov et al., 2005). These models are computationally efficient and can thus be used for longer coupled climate-carbon cycle simulations with anthropogenic perturbation (e.g. Lunt et al., 2004).

Experiments with complex three-dimensional earth system models (including cycles of terrestrial as well as marine carbon) were performed by Cox et al. (2000), Friedlingstein et al. (2001, 2003), Govindasamy et al. (2005), Fung et al. (2005) and Friedlingstein et al. (2006). Various types of anthropogenic forcing were applied, either prescribing the concentration of $\mathrm{CO}_{2}$, or prescribing the emissions of $\mathrm{CO}_{2}$ into the system. These complex model experiments are usually limited to a few hundred years, and do not include ice sheet dynamics.

The studies with complex models mentioned above are typically describing the carbon cycle for a historical period to present-day, followed by scenario calculations for the 21st century, in which the atmospheric $\mathrm{CO}_{2}$ concentration increases and climate changes accordingly. In this study, we will explore the behaviour of the carbon cycle beyond the 21st century. Under the assumption that the $\mathrm{CO}_{2}$ emissions will decline beyond 2100, the coupled system of the terrestrial, marine and atmospheric carbon cycle, as well as the physical climate system, will move towards a new equilibrium state. The range of possibilities for this new equilibrium state is represented by scenario experiments with the IPCC SRES emission scenarios A2, A1B and B1 for 2001-2100 (Nakićenović et al., 2000), followed by an assumed exponential decay for the period after the end of the 21st century. Towards the end of this millennium, the total emissions of $\mathrm{CO}_{2}$ in our experiments sum up to roughly $2000 \mathrm{Pg} \mathrm{C}, 4000 \mathrm{Pg} \mathrm{C}$ and $6500 \mathrm{Pg} \mathrm{C}$, with according changes in climate. There is a mutual interaction between climate and terrestrial biosphere. Not only is the terrestrial biosphere responding to changes in climate and atmospheric $\mathrm{CO}_{2}$ concentration; the changes in terrestrial carbon uptake and thus atmospheric $\mathrm{CO}_{2}$ concentration, and changes in land surface properties, can influence the climate as well. The aim of this paper is to study the biogeophysical and biogeochemical role of the terrestrial biosphere in long-term anthropogenic climate change simulations, and estimate the relevance of these feedbacks for the simulated climate change.

An overview of the physical and biogeochemical changes in the earth system in the baseline scenario experiments can be found in Mikolajewicz et al. (2007), showing that changes in the ocean circulation play a key role in climate change, as well as in the carbon uptake by the oceans. The present paper analyses the role of the terrestrial biosphere with respect to anthropogenic changes of the earth system in detail. Specific aspects are investigated using sensitivity experiments.

\section{Method}

\subsection{Model}

The effects of changes in the terrestrial biosphere on climate were studied in a complex earth system model (Mikolajewicz et al., 2007), consisting of a coupled atmosphere-ocean general circulation model (ECHAM3-LSG, Mikolajewicz and Voss, 2000; Voss and Mikolajewicz, 2001), a marine carbon cycle model (HAMOCC, Maier-Reimer, 1993), a dynamic global vegetation model (LPJ, Sitch et al., 2003) and a thermomechanical ice sheet model (SICOPOLIS, Greve, 1997). The atmosphere model and the vegetation model run on a T21 grid $\left(5.6^{\circ} \times 5.6^{\circ}\right)$, the ocean and ocean biogeochemistry on an Arakawa E- grid (Arakawa and Lamb, 1977) of effectively $4.0^{\circ} \times 4.0^{\circ}$ and the ice sheet model runs on an $80 \mathrm{~km}$ grid. These rather coarse resolutions, together with a periodically synchronous coupling (Sausen and Voss, 1996; Mikolajewicz et al., 2007), enable for integrations over long periods ( 1000 years).

The Lund-Potsdam-Jena dynamic global vegetation model (LPJDGVM, Sitch et al., 2003) calculates the distribution of plant functional types (PFTs) over the globe, as well as carbon storage in vegetation, litter and soil. A grid cell can contain several PFTs, each of which contains four living biomass carbon pools and three litter pools, based on an average individual. Each grid cell contains two soil carbon pools common to all PFTs. Uptake and release of carbon are calculated from photosynthesis and respiration; shifts between the carbon pools include biomass burning and plant mortality. Vegetation distribution as well as carbon cycle processes are calculated from climate variables provided by the atmosphere. The main variables are temperature, soil moisture and radiation. The model simulates potential vegetation, and does not consider human-induced changes such as land use change or deforestation.

From the vegetation model, both biogeophysical feedbacks and biogeochemical feedbacks to the atmosphere are calculated. The biogeophysical feedbacks are caused by changes in the land surface. Once a year, monthly values for background albedo (albedo of the surface without snow cover), vegetation fraction, forest fraction and roughness length are provided to the atmosphere model. Vegetation fraction and forest fraction are produced by the vegetation model, surface background albedo and vegetation roughness length are derived from PFT-specific values, scaled with their respective cover fractions (Schurgers et al., 2007). Biogeochemical feedbacks are a result of uptake and release of $\mathrm{CO}_{2}$ : once a year a net global flux of $\mathrm{CO}_{2}$ from the terrestrial biosphere is calculated.

\subsection{Experiments}

A set of experiments with prescribed anthropogenic $\mathrm{CO}_{2}$ emissions was carried out with the complex earth system model (Table 1). In order to study the long-term stabilization of the carbon cycle and the physical climate system after emissions of $\mathrm{CO}_{2}$, scenarios for the emission of $\mathrm{CO}_{2}$ were used in which the historical emissions as well as the IPCC SRES projections for the 21st century were combined with a gradual decay of the emissions after 2100. Historical data from 1750 to 2000 were used for emissions from fossil fuel and cement production (Marland et al., 2005) and land use change (Houghton and Hackler, 2002). From 2000 to 2100, three different ensembles of climate simulations were performed, forced with emissions according to IPCC SRES scenarios A1B, A2 and B1 (Nakićenović et al., 2000).

Table 1

Overview of the experiments

\begin{tabular}{|c|c|}
\hline CTRL & Coupled control run without $\mathrm{CO}_{2}$ emissions \\
\hline HIST & Historical emissions $1750-2000$ ( 5 ensemble members) \\
\hline A1B & $\begin{array}{l}\text { emissions according to IPCC SRES scenario A1B 2001-2100, } \\
\text { exponential decay after } 2100 \text { ( } 5 \text { ensemble members, 2001-3000) }\end{array}$ \\
\hline $\mathrm{A} 2$ & $\begin{array}{l}\text { Emissions according to IPCC SRES scenario A2 2001-2100, } \\
\text { exponential decay after } 2100 \text { ( } 3 \text { ensemble members, 2001-3000) }\end{array}$ \\
\hline B1 & $\begin{array}{l}\text { Emissions according to IPCC SRES scenario B1 2001-2100, } \\
\text { exponential decay after } 2100 \text { ( } 3 \text { ensemble members, 2001-3000) }\end{array}$ \\
\hline$\ldots-280$ & $\begin{array}{l}\text { Atmosphere radiative forcing with } 280 \mathrm{ppm} \\
\text { (1 experiment for each scenario) }\end{array}$ \\
\hline ...-noBGP & $\begin{array}{l}\text { With prescribed biogeophysical land surface and ice sheets } \\
\text { ( } 1 \text { experiment for scenario A2, and } 1 \text { control run) }\end{array}$ \\
\hline ...-noBGC & $\begin{array}{l}\text { Without terrestrial carbon uptake/release } \\
\text { (1 experiment for scenario A2) }\end{array}$ \\
\hline ‘CO 2 only’ & $\begin{array}{l}\text { Offline run with the vegetation model, forced with } \mathrm{CO}_{2} \text { from the } \\
\text { coupled experiment and control run climate }\end{array}$ \\
\hline $\begin{array}{l}\text { ‘climate change } \\
\text { only’ }\end{array}$ & $\begin{array}{l}\text { Offline run with the vegetation model, forced with climate from th } \\
\text { coupled experiment and control run } \mathrm{CO}_{2}\end{array}$ \\
\hline
\end{tabular}




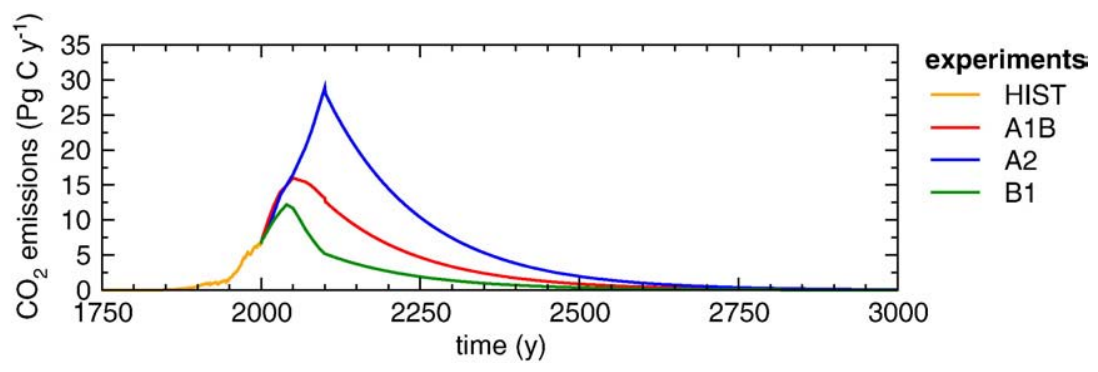

Fig. 1. Prescribed $\mathrm{CO}_{2}$ emissions for the IPCC SRES scenario experiments.

These scenarios are defined only up to 2100 . In order to stabilize the system after 2100 , a gradual decay of the emissions was assumed to be suitable. The decay was prescribed exponentially with a time constant of 150 years, starting from the IPCC SRES emission rates at 2100 (Fig. 1). The magnitude of the time constant is arbitrary, and was chosen to obtain a reduction of the emission by one order of magnitude in approximately 300 years. A control run was performed without $\mathrm{CO}_{2}$ emissions, with the atmospheric $\mathrm{CO}_{2}$ concentration calculated prognostically. For the period 1750-2000, an ensemble of five experiments was performed, starting from different years of the control run. For the scenario period (2001-3000), five ensemble members were performed for the A1B scenario, for the A2 and B1 scenarios three ensemble members each were performed. In order to reduce the computational requirements of the model, the experiments were performed using a periodically synchronous coupling (Sausen and Voss, 1996; Mikolajewicz et al., 2007). During synchronous intervals of 2 years, the earth system model was run in a fully coupled mode. These synchronous intervals were followed by asynchronous intervals of 8 years in which the ocean surface was driven by a non-linear energy balance model at the surface rather than with surface conditions from the atmosphere GCM. The vegetation model and ice sheet model were driven by atmospheric variables from a climate archive that consists of the latest 8 simulated atmosphere years from the synchronous periods.

The sets of scenario experiments were accompanied by two experiments with the A2 scenario to analyse the biogeophysical and biogeochemical role of the terrestrial biosphere, respectively. One experiment was performed in which the biophysical effects of the terrestrial biosphere were ignored: the atmosphere and ocean model were driven by the original land surface parameterization rather than the interactively calculated parameters from the terrestrial biosphere (A2-noBGP). The carbon cycle effects from the terrestrial biosphere were taken into account, and the biophysical part of the terrestrial biosphere was still included in the experiments for analysis purposes, although it was not allowed to affect the atmosphere model. Another experiment was performed in which the uptake and release of carbon by the terrestrial biosphere were not taken into account for the changes in the atmospheric $\mathrm{CO}_{2}$ concentration: the carbon balance was calculated based on atmosphere and ocean exchange only (A2noBGC). Effects of changes in vegetation on land surface properties were taken into account.

In another set of experiments, climate change due to increased $\mathrm{CO}_{2}$ concentration was suppressed by setting the atmospheric $\mathrm{CO}_{2}$ concentration for radiative forcing to a pre-industrial level of $280 \mathrm{ppm}$, but

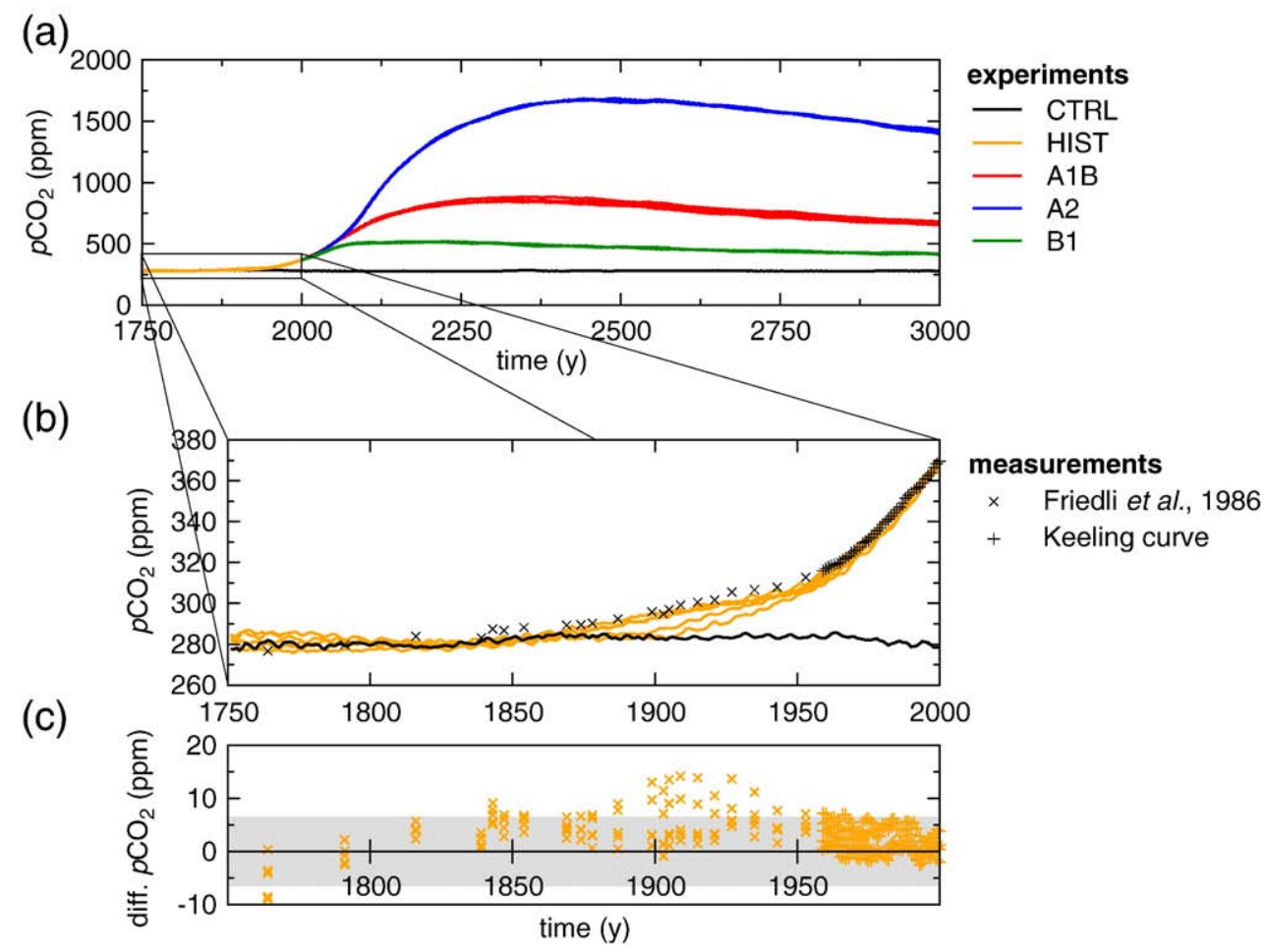

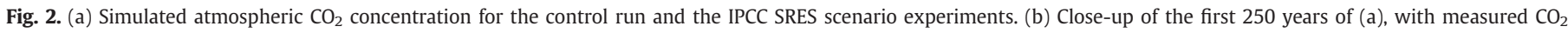

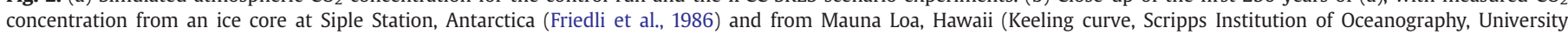
of California). (c) Difference between simulated and measured $\mathrm{CO}_{2}$ concentration as in (b). The grey area indicates the uncertainty ( \pm 2 standard deviations) of the control run. 
Table 2

Overview of modelled $\mathrm{CO}_{2}$ concentrations (ppm) for 2100 for different studies with the IPCC SRES scenarios

\begin{tabular}{llll}
\hline & B1 & A1B & A2 \\
\hline ISAM $^{1}$ & $549\left(490-603^{7}\right)$ & $717\left(630-790^{7}\right)$ & $856\left(755-936^{7}\right)$ \\
Bern-CC $^{1,2}$ & $540\left(486-681^{7}\right)$ & $703\left(617-918^{7}\right)$ & $836\left(735-1080^{7}\right)$ \\
IPSL-CM2 $^{3}$ & & & 770 \\
INCCA $^{4}$ & & 661 & 732 \\
NCAR CSM1.4 $^{5}$ & & & 792 \\
C4MIP $^{6}$ & & $656\left(652-661^{8}\right)$ & $730-1020$ \\
this study & $506\left(504-510^{8}\right)$ & $778\left(772-783^{8}\right)$ \\
\hline
\end{tabular}

${ }^{1}$ Houghton et al. (2001); ${ }^{2}$ Joos et al. (2001); ${ }^{3}$ Dufresne et al. (2002);Friedlingstein et al. (2003); ${ }^{4}$ Govindasamy et al. (2005); ${ }^{5}$ Fung et al. (2005); ${ }^{6}$ Friedlingstein et al. (2006), model intercomparison with 11 models; ${ }^{7}$ range calculated with low and high $\mathrm{CO}_{2}$ sensitivity of the atmosphere model; ${ }^{8}$ range of the ensemble members.

the terrestrial and marine carbon cycle components were simulated with enhanced $\mathrm{CO}_{2}$ concentrations.

Moreover, offline experiments were performed for the period 2001-3000 with the terrestrial biosphere component only, in which the model was forced with control run climate and scenario run atmospheric $\mathrm{CO}_{2}$ concentration (referred to as ' $\mathrm{CO}_{2}$ only') or with scenario run climate and control run atmospheric $\mathrm{CO}_{2}$ concentration (referred to as 'climate change only'). These experiments are meant to determine the effects of $\mathrm{CO}_{2}$ change and climate change separately. All experiments are summarized in Table 1.

\section{Results}

The biogeophysical and biogeochemical interactions between the terrestrial biosphere and the atmosphere were analysed separately, as well as the mutual influence of biogeophysics and biogeochemistry. We focus on the terrestrial biosphere here, with a short overview of the changes in the physical climate system.

\subsection{Climate change and atmospheric $\mathrm{CO}_{2}$ concentration}

The simulated $\mathrm{CO}_{2}$ concentration of the simulations is shown in Fig. 2a. The maximum concentrations for the IPCC SRES scenarios reach values of about $520 \mathrm{ppm}$ (B1, around 2200), 855 ppm (A1B, around 2330) and $1680 \mathrm{ppm}$ (A2, around 2500). At the end of the experiment, all scenario simulations show a slightly decreasing trend in the atmospheric $\mathrm{CO}_{2}$ concentration, caused by the combination of negligible emissions and a continuing uptake of carbon by the ocean. A comparison with measured atmospheric $\mathrm{CO}_{2}$ concentrations for the period up to 2000 (Fig. 2b and c) shows that the model is able to capture the measured increase during the last century quite well. Most of the ensemble members stay within the range given by \pm 2 standard deviations of the control run atmospheric $\mathrm{CO}_{2}$ concentration. Between 1875 and 1950, two of the ensemble members get out of the range of the natural variability in the control run (Fig. 2c), due to a larger uptake of carbon in the terrestrial biosphere. This takes place in several different regions for both experiments.

Several other studies with coupled climate-carbon cycle models were performed in which the IPCC SRES scenarios were used (Table 2). This study predicts $\mathrm{CO}_{2}$ concentrations for the IPCC SRES scenarios around 2100 below the estimates from the IPCC Third Assessment Report (Houghton et al., 2001), but the concentrations agree reasonably with recent simulations from other earth system models (Dufresne et al., 2002; Govindasamy et al., 2005; Fung et al., 2005; Friedlingstein et al., 2006). Differences are caused by changes both in the uptake by the ocean and in the uptake by the terrestrial biosphere.

The increase in atmospheric $\mathrm{CO}_{2}$ (Fig. 2a) causes an increase in nearsurface air temperature of $1.3 \mathrm{~K}(\mathrm{~B} 1), 3.0 \mathrm{~K}(\mathrm{~A} 1 \mathrm{~B})$ and $4.9 \mathrm{~K}$ (A2) for the period 2801-3000 compared to the pre-industrial control run average (Fig. 3). Besides atmospheric temperature, the strength of the zonally integrated meridional overturning in the North Atlantic (NAMOC), responsible for the relatively mild climate of northwest Europe due to its strong contribution to the northward oceanic heat transport, is one of the key concerns of anthropogenic climate change. Until 2100, all simulations show only a slight weakening of the overturning circulation in the North Atlantic due to the changes in climate (Mikolajewicz et al., 2007). However, after 2100 the North Atlantic meridional overturning circulation reacts strongly to the changes in climate. Its reaction depends highly on the applied scenario: ranging from a temporal decrease in strength for the B1 scenario experiments to a complete collapse for the A2 scenario experiments. In the A1B scenario experiments the North Atlantic meridional overturning circulation appears to be close to a bifurcation point: two of the five ensemble experiments show a collapse of the deep water formation in the North Atlantic between 2150 and 2250 , one shows a collapse between 2600 and 2750 , and two show only a temporal weakening as in the B1 experiments (see Mikolajewicz et al., 2007, for more details). As a consequence, the North Atlantic heat transport differs substantially between the individual ensemble members. The collapse of the meriodional overturning and the associated reduction in ocean heat transport causes in general a massive cooling over the North Atlantic, thereby influencing the land surface as well. Even 2000 years after complete suppression of the anthropogenic $\mathrm{CO}_{2}$ emissions the North Atlantic meridional overturning circulation did not return to its present mode of operation in all simulations with a complete shutdown.

The major patterns of climate change are a direct response to the increasing $\mathrm{CO}_{2}$ concentration. The magnitude of this response is

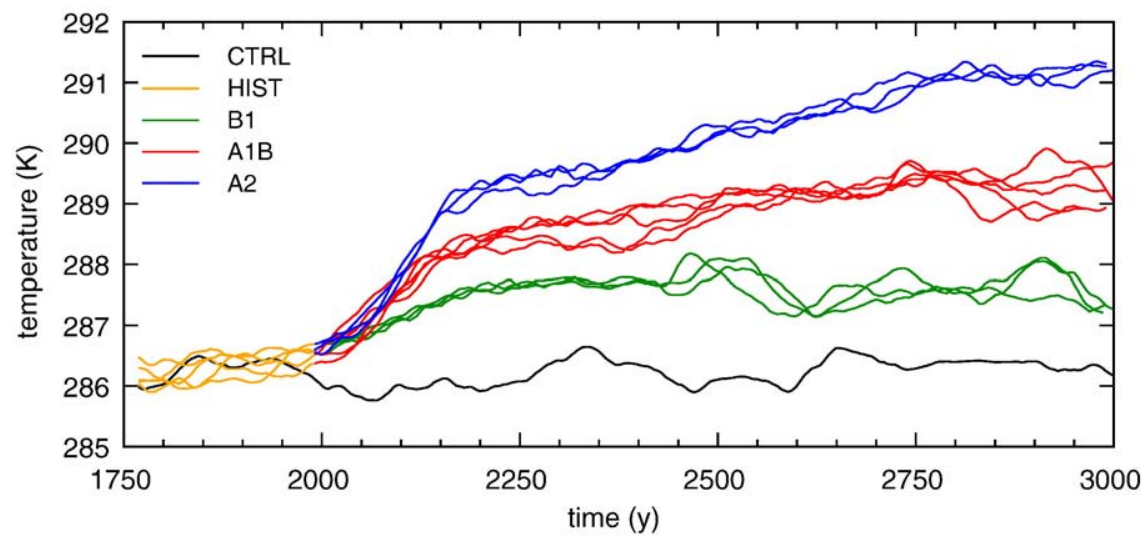

Fig. 3. Global mean near-surface air temperature for the control run and the emission scenario experiments. Shown are 20-year running means. 
partially determined by the terrestrial biosphere. It plays a role in the biogeochemistry of the earth, and changes in the land surface cause biogeophysical effects to the atmosphere. We discuss each of these roles below, as well as the combination of both roles.

\subsection{Land surface changes and biogeophysical interactions}

The changes in climate related to an increase of the $\mathrm{CO}_{2}$ concentration, as well as the changes in $\mathrm{CO}_{2}$ concentration itself, favour shifts in the vegetation pattern. The anomalies for the different scenarios all show the same features as the average of the A1B simulations (Fig. 4), but the extent differs per scenario, with larger anomalies for the A2 ensemble simulations and smaller anomalies for the B1 ensemble simulations. Tropical trees show an expansion in southern Africa and central South America, where they suppress the temperate trees and $C_{3}$ herbs. Broadleaf summergreen trees in the temperate zone show a clear northward shift in North America and Eurasia, as do the needleleaf trees (evergreen and summergreen) in the boreal zone. Herbs increase mainly in the northern parts of North America and Eurasia, as well as in the dry regions in central Asia. The area of bare soil increases in northern Africa and the Middle East (Fig. 4a).
Most of the changes in the mid and high latitudes are caused by changes in the climate, as can be deduced from the "climate change only' experiments (Fig. 4b). At lower latitudes, especially the dry regions around $30^{\circ} \mathrm{N}$ and $30^{\circ} \mathrm{S}$, remarkable changes take place in the ' $\mathrm{CO}_{2}$ only' simulations as well. Areas with mainly $\mathrm{C}_{3}$ grasses in North and South America are replaced by forest (Fig. 4b). This effect is caused by an increase in water use efficiency due to the high $\mathrm{CO}_{2}$ concentrations, which enables plants to grow in drier places due to a reduction of water loss. In the experiments with global warming, most of these changes due to $\mathrm{CO}_{2}$ are counteracted by changes in the precipitation pattern: the most important semi-arid regions (northern Africa, central Asia) become drier, thereby reducing plant growth and carbon storage.

The changes at high latitudes take place slowly compared to the tropics. Boreal forest expansion and forest growth are relatively slow processes, due to low temperatures and small rates of net primary production (NPP). However, forest growth in the high latitudes shows a clear response to the decrease in temperature over the land area around the North Atlantic that occurs in the experiments in which the meridional overturning circulation collapses (Mikolajewicz et al., 2007) (Fig. 5). Both the A1B experiments with a reduced North Atlantic

(a)
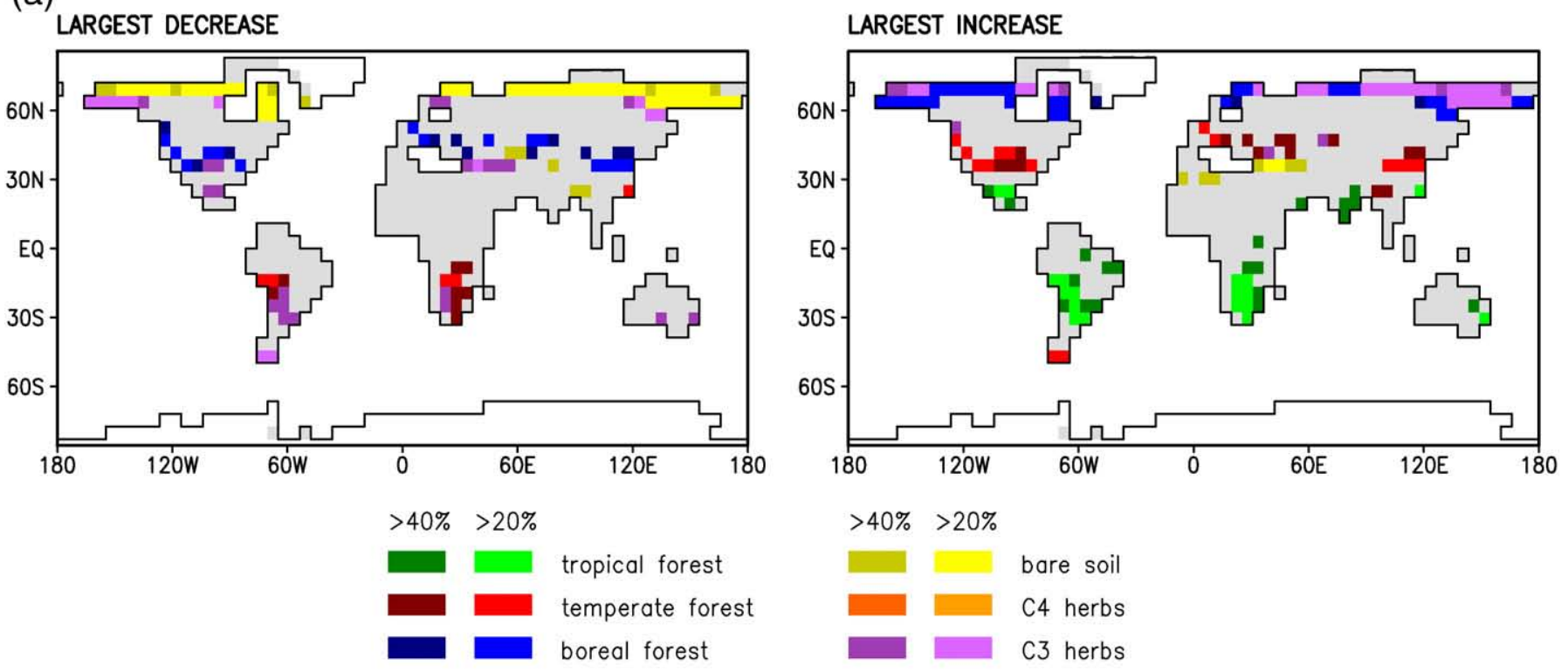

(b)

\section{LARGEST INCREASE 'climate change only'}

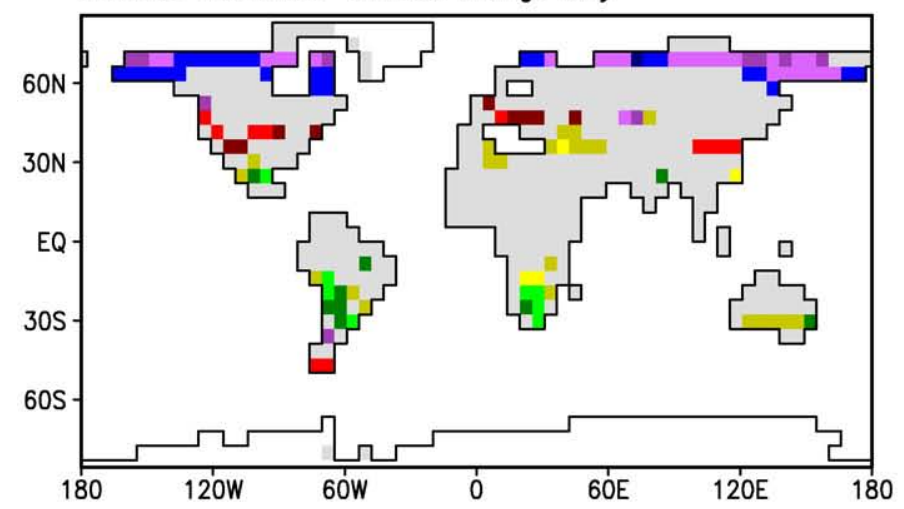

LARGEST INCREASE 'CO2 change only'

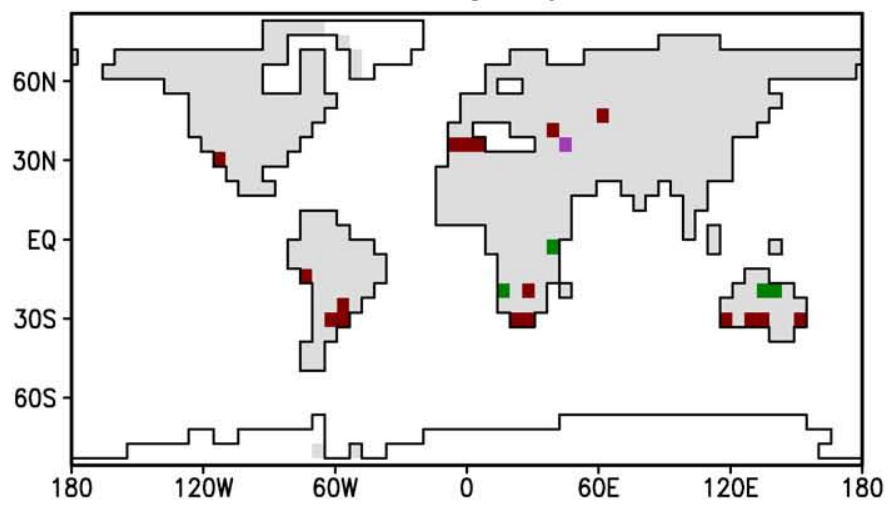

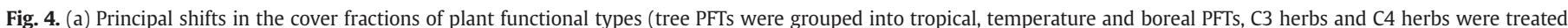

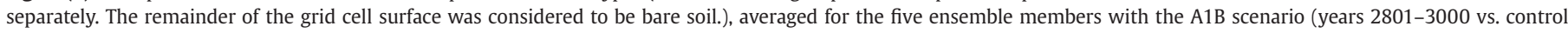

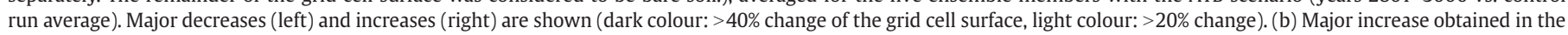
'climate change only' (left) and ' $\mathrm{CO}_{2}$ change only' (right) experiments. 


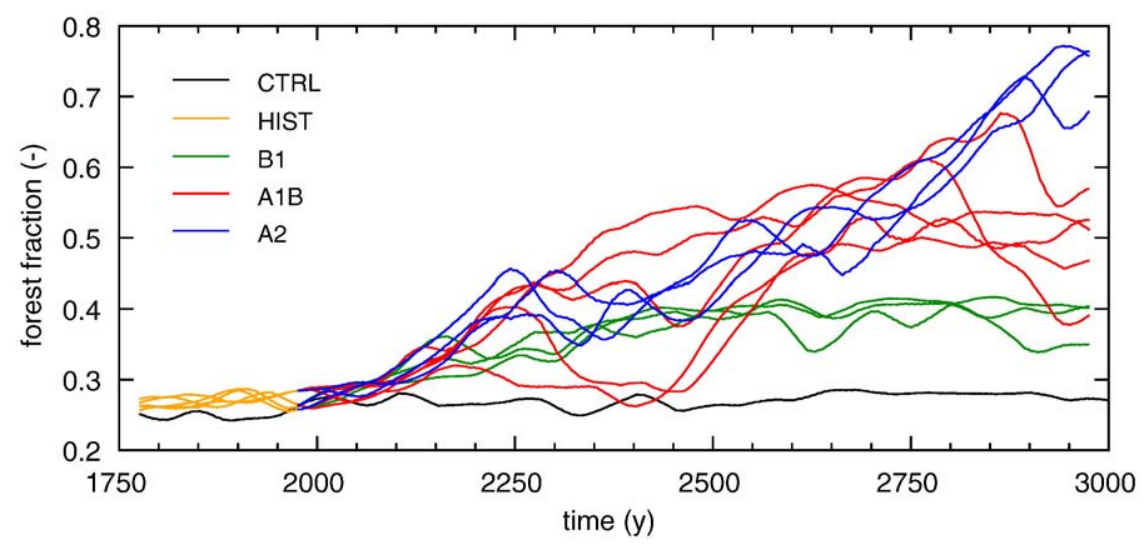

Fig. 5. Forest fraction for the land surface $60^{\circ}-90^{\circ} \mathrm{N}$ (excluding ice sheets). Shown are 50 year running means.

meridional overturning circulation and the A2 experiments exhibit a decrease of forest fraction around 2250 , with a recovery afterwards. For the A1B experiments, the temperature decrease around the North Atlantic reduces forest fraction to pre-industrial levels. For the A2 experiment the response is less pronounced: due to the large global temperature increase the negative temperature anomaly over the Atlantic does not affect the increase in forest fraction as much as in the A1B scenario experiments. For the year 3000 , simulated forest fraction between $60^{\circ}$ and $90^{\circ} \mathrm{N}$ increased from the pre-industrial level of $25 \%$ to 40\% (B1), 50-55\% (A1B) and 70\% (A2) (Fig. 5).

At high latitudes, the changes in forest cover cause a shift in the albedo of the land surface: forests absorb more of the incoming radiation than grasses, and thus appear to be "darker". Additionally, the albedo of snow-covered areas is influenced by the presence of forests: snow-covered forests have a lower albedo than snow-covered grasslands. These changes in surface albedo are most likely the major biogeophysical feedback of natural vegetation changes to the atmosphere for warming climate in the future. Many studies were performed either afforesting or deforesting high latitudes in climate models. For example, Otterman et al. (1984) performed experiments reducing the albedo of the high latitudes, thereby mimicking forest growth, and Bonan et al. (1992), Thomas and Rowntree (1992) and Douville and Royer (1997) performed experiments removing the forest in the high latitudes. They all showed that the climate of the high latitudes is sensitive to changes in the distribution of forests and tundra.

In our simulations, the effect of changes in vegetation distribution on climate can be analysed by comparing the A2 experiments with the A2-noBGP experiment. In the latter experiment, land surface properties were prescribed according to the original ECHAM3 parameterization, in order to have the climate not affected by biogeophysical feedbacks from land. Fig. 6 shows the changes in albedo and changes in temperature for the high latitudes of the northern hemisphere. Due to higher temperatures (Fig. 6b), both snow cover and sea ice cover decrease in the experiment without interactive land surface (A2-noBGP), thereby decreasing the surface albedo (Fig. 6a). For the A2 simulations with interactive land surface (A2), albedo over land changes additionally due to shifts in the vegetation pattern. In the regions where bare soil was replaced by grasses and forests (Fig. 4), albedo decreases up to $25 \%$.

This change in albedo causes an additional warming, up to $2 \mathrm{~K}$ (Fig. 6c). The largest increase in temperature induced by land surface changes is simulated for northern Siberia, in the areas where albedo changes due to forest growth. This warming is restricted to the high latitudes of the northern hemisphere, resulting in a global average temperature increase of $0.26 \mathrm{~K}$. A part of this global signal is caused by a slightly higher atmospheric $\mathrm{CO}_{2}$ concentration in the $\mathrm{A} 2$ experiments compared to the A2-noBGP experiment, which will be discussed below. The patterns of temperature increase for both the $\mathrm{A} 2$ and the
A2-noBGP experiments are dominated by a negative anomaly over the North Atlantic and an overall positive anomaly for the rest of the world. The negative anomaly over the North Atlantic is caused by the decrease of the meridional overturning circulation, which offsets the global warming due to the enhanced $\mathrm{CO}_{2}$ concentrations here. The additional warming due to land surface changes in the A2 experiment in Fig. $6 \mathrm{c}$ is only a minor effect compared to the overall temperature increase (Fig. 6b), with a global average of $4.9 \mathrm{~K}$.

\subsection{Carbon storage and biogeochemical interactions}

A second effect of the terrestrial biosphere is related to its function in the global carbon cycle, influencing the atmospheric $\mathrm{CO}_{2}$ concentration by uptake or release of carbon. The anthropogenic emissions of $\mathrm{CO}_{2}$ lead to an increase in atmospheric concentration, followed by an uptake of $\mathrm{CO}_{2}$ in the ocean and the terrestrial biosphere. Total increases of marine and terrestrial carbon storage are shown in Fig. 7. During the 20th and 21st century, the uptake rates of $\mathrm{CO}_{2}$ by the terrestrial biosphere and the ocean are of roughly equal size. Whereas the ocean remains a sink for carbon up to the year 3000 , mainly due to a continuing relatively slow transport of carbon into the deep ocean, carbon storage in the terrestrial biosphere levels off after year 2300 and even declines slightly along with the atmospheric $\mathrm{CO}_{2}$ concentration thereafter (Fig. 2). The ocean is the dominant sink of carbon on the long term due to its large capacity to store carbon and the dissolution of calcareous sediments on these timescales. By 3000, the total amounts of emitted $\mathrm{CO}_{2}$ equal $1970 \mathrm{Pg} \mathrm{C}$ (B1), $3810 \mathrm{Pg}$ C (A1B) and $6570 \mathrm{Pg} \mathrm{C}$ (A2). The ocean has taken up $1260 \mathrm{Pg} \mathrm{C}$ (B1), $2170 \mathrm{Pg} C$ (A1B) and $3010 \mathrm{Pg} \mathrm{C}$ (A2), and the terrestrial biosphere has taken up $420 \mathrm{Pg} \mathrm{C}$ (B1), $810 \mathrm{Pg} \mathrm{C}$ (A1B) and $1130 \mathrm{Pg} \mathrm{C}$ (A2) of these emissions, the remainder lasted in the atmosphere. This leads to an increase of the airborne fraction with increasing $\mathrm{CO}_{2}$ emissions: from $15 \%$ for the B1 experiments to 35\% for the A2 experiments for 2801-3000.

The relative uptake of carbon by the terrestrial biosphere and the ocean are lower for the A2 experiments than for the B1 and A1B experiments. The breakdown of the North Atlantic meridional overturning circulation involves larger time constants for the ocean conveyor belt, which causes the A2 scenario to be further away from an equilibrium state (Fig. 7), whereas the B1 and A1B experiments are much closer to a steady state. Besides that, a saturation of the terrestrial biosphere with respect to $\mathrm{CO}_{2}$ is occurring: uptake rates decrease at higher concentration of $\mathrm{CO}_{2}$. Even with an extension of these experiments for several thousand years after the year 3000, the ocean remains a sink for carbon (see Mikolajewicz et al., 2007, Fig. 19), whereas terrestrial biosphere carbon decreases slightly.

The increase in carbon storage on land due to $\mathrm{CO}_{2}$ fertilization is partly counteracted by a decrease in storage due to global warming. For both the marine and the terrestrial carbon storage, the effect 
(a)
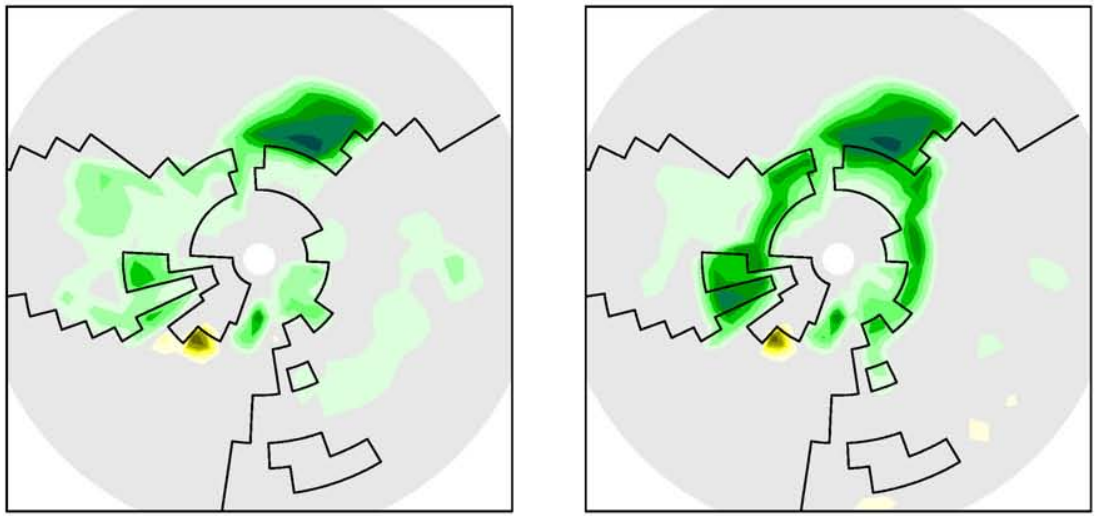

(b)
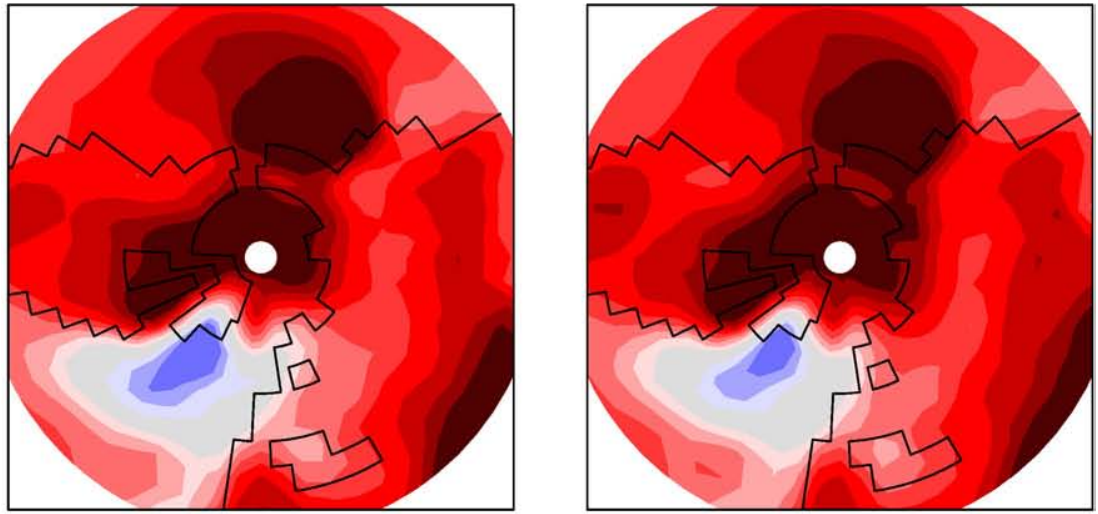

(c)
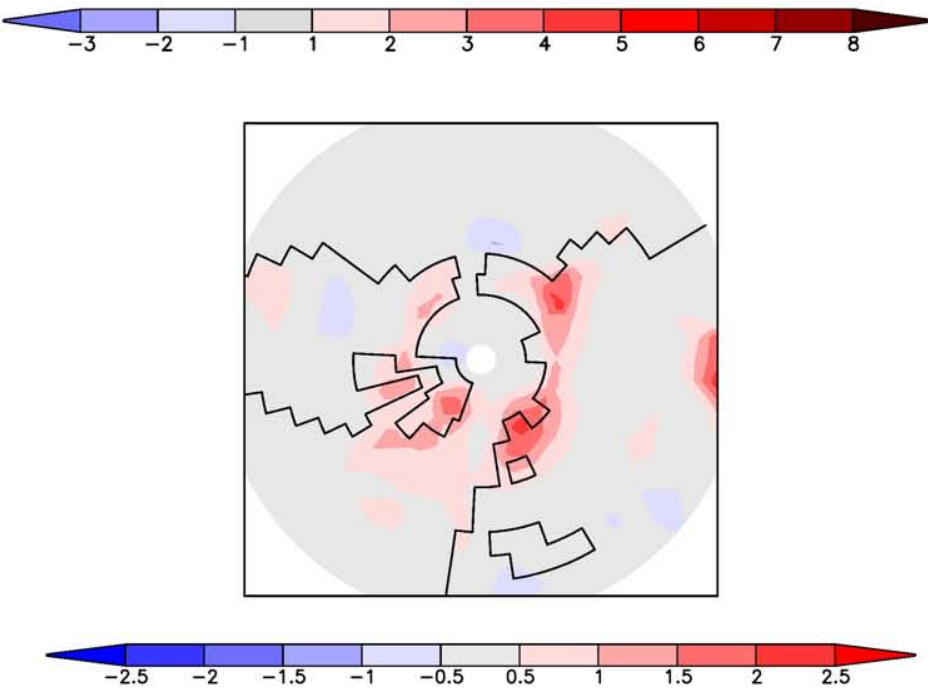

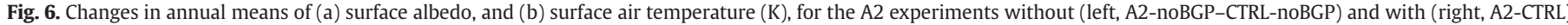
interactive land surface for 2801-3000. (c) difference in temperature anomaly (K) for A2-A2-noBGP for 2801-3000.

of climate change depends on the scenario. In the emission scenarios B1-280, A1B-280 and A2-280 with pre-industrial radiative forcing and no climate feedback, carbon storage in the terrestrial biosphere is higher than in the experiments with feedbacks between climate and carbon cycle (Fig. 7). This increase in storage, induced by $\mathrm{CO}_{2}$ fertilization, is reduced as a result of changes in climate. This reduction can be calculated from the difference between the fully coupled experiments and the experiments without climate change. For the period
2801-3000, the reduction in total carbon storage for the terrestrial biosphere was $16 \%$ (B1), 22\% (A1B) and 34\% (A2). For the marine carbon storage, the situation changes from an increase in carbon storage of $5 \%$ and $2 \%$ for the $\mathrm{B} 1$ and $\mathrm{A} 1 \mathrm{~B}$ experiments respectively to a decrease of $9 \%$ for the A2 scenario, all for the period 2801-3000. From a study with the same earth system model (Winguth et al., 2005) for experiments with atmospheric $\mathrm{CO}_{2}$ concentrations fixed at $3 \times$ and $4 \times$ the pre-industrial level of $280 \mathrm{ppm}$, the reduction in terrestrial carbon 
(a)
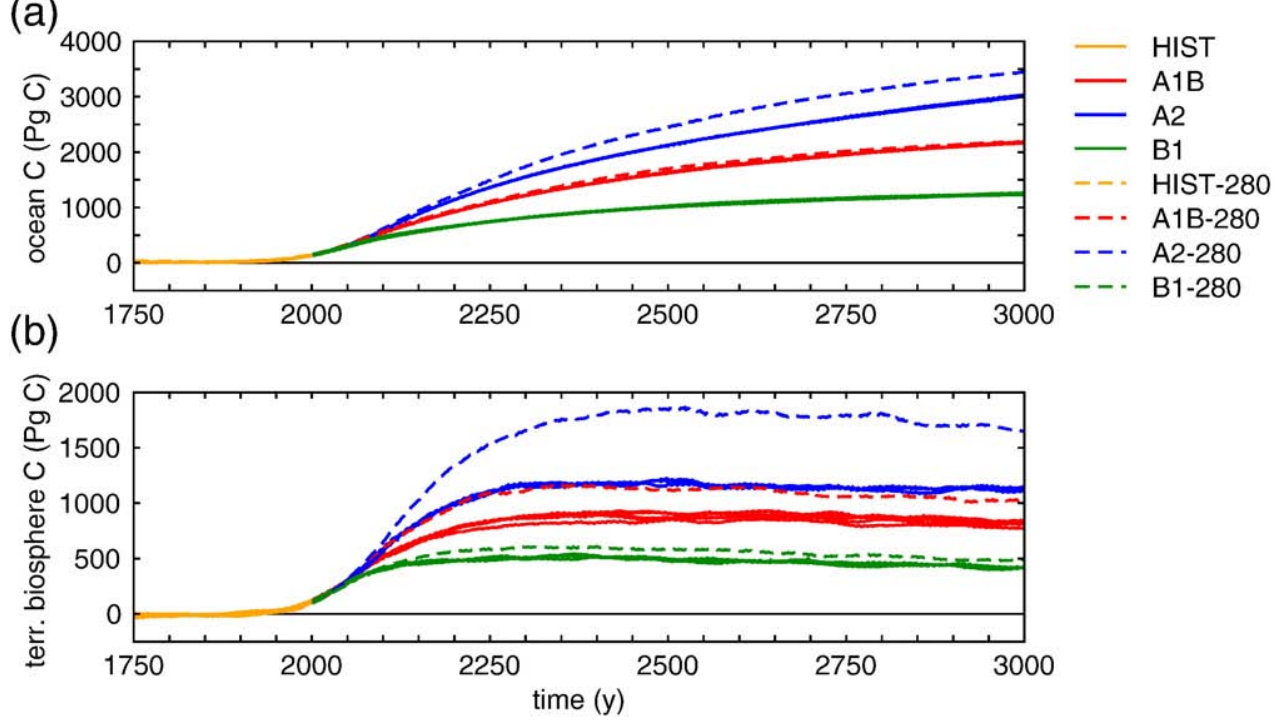

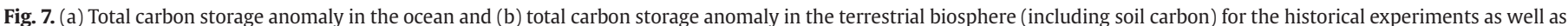
the IPCC SRES scenario experiments, both compared to the average of the pre-industrial control run.

(a)

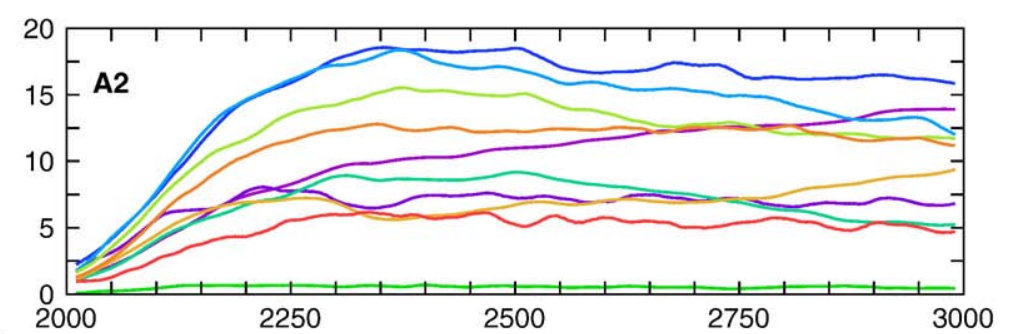

(b)

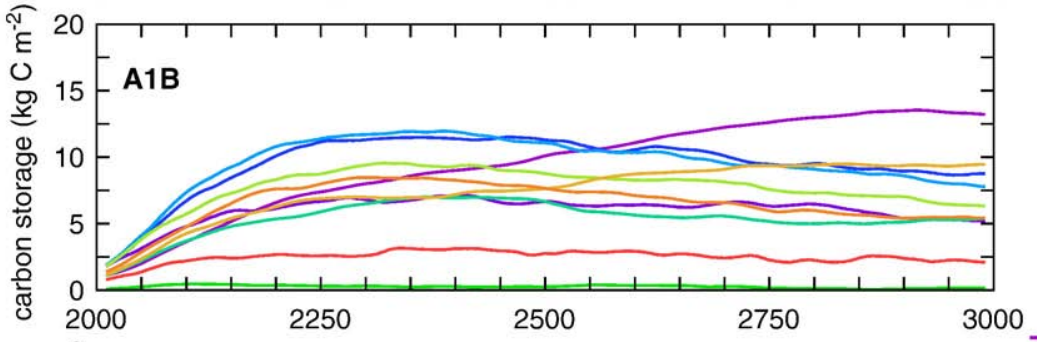

(c)
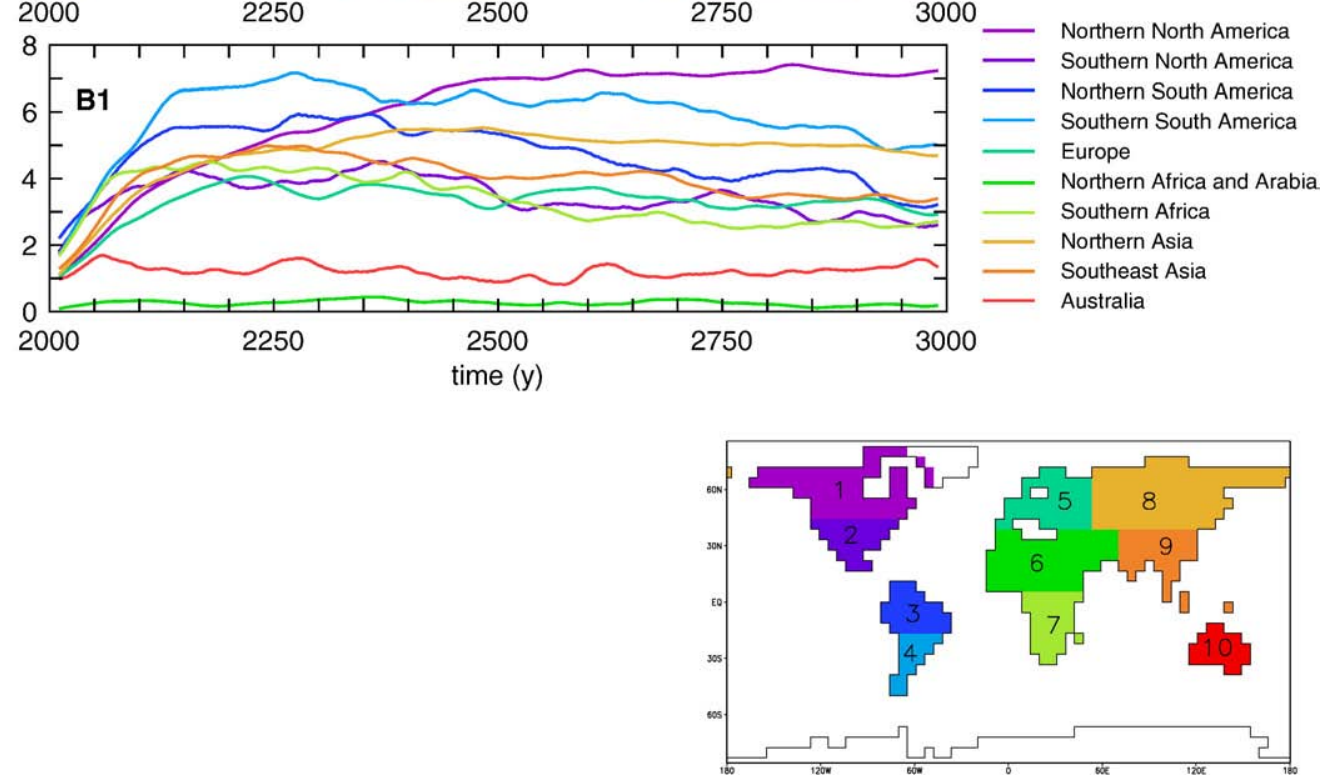

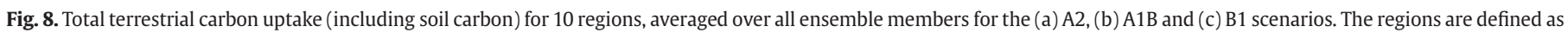
in the map, shown are 20-year running means. 
storage due to climate change was $37 \%$ for $3 \times \mathrm{CO}_{2}$ and $43 \%$ for $4 \times \mathrm{CO}_{2}$ after 1000 years. Marine carbon storage was found to decrease in both experiments due to climate change: reductions of $17 \%$ for $3 \times \mathrm{CO}_{2}$ and $22 \%$ for $4 \times \mathrm{CO}_{2}$ were simulated. The differences to our results are caused by a different setup: whereas Winguth et al. (2005) use a fixed $\mathrm{CO}_{2}$ concentration at the end of their experiments, which implies emissions roughly the size of the ocean uptake at the end, we use negligible $\mathrm{CO}_{2}$ emissions at the end for this study.

In the fully coupled experiment, carbon storage is enhanced almost everywhere on land, but the rate of increase differs greatly. Ten regions were defined for which carbon storage was calculated individually (Fig. 8). The regions react differently to the combined effects of $\mathrm{CO}_{2}$ and climate change. Fastest and largest increase was simulated for the tropical regions (northern and southern South America, southern Africa). The carbon storage in these regions tends to follow more or less the atmospheric $\mathrm{CO}_{2}$ curve as shown in Fig. 2a. Northern North American and northern Asian carbon storage evolves differently, the amount of carbon increases steadily till the year 3000, reaching relatively high levels of carbon storage at the end. For these regions, the slow expansion of forests (Fig. 5), and the slow buildup of the soil carbon pool, are of major importance for carbon uptake. Grasslands or deserts (northern Africa and the Arabian peninsula, Australia) have lowest absolute storage of carbon, they are relatively unimportant with respect to the biogeochemical role of the biosphere.

The offline experiments, in which the vegetation model was driven with either increasing $\mathrm{CO}_{2}$ concentration or changes in climate, were used to determine the importance of $\mathrm{CO}_{2}$ fertilization and climate change for the increase in carbon storage shown above. Fig. 9 shows the fraction of the increase in carbon storage that is obtained in the ' $\mathrm{CO}_{2}$ only' or 'climate change only' experiments relative to the change in the fully coupled experiments. Except for northern North America, climate change reduces the carbon uptake, and the increase of carbon storage for all regions, as was shown in Fig. 8, is due to $\mathrm{CO}_{2}$ increase only. Largest ratios between carbon storage in the experiments with either climate change or $\mathrm{CO}_{2}$ effects included and the experiments in which both influences are represented are obtained for northern Africa and Arabia. Climate change has a big reducing effect here, because the sparse vegetation present here is suffering highly from the drier conditions, whereas changes in $\mathrm{CO}_{2}$ are helping them to stand these due to a higher water use efficiency. Relatively large negative effects of climate change are simulated for southern North America, Europe and northern Asia in the A2 scenario. For shorter timescales than those discussed here $(\sim 100$ years $)$, the effects at high latitudes are usually smaller than those reported here for long-term experiments, because of the slow changes occurring here.

An additional experiment was performed to quantify the biogeochemical role of the terrestrial biosphere (HIST-noBGC and A2noBGC). In this experiment, the uptake or release of carbon by the terrestrial biosphere did not influence the atmospheric $\mathrm{CO}_{2}$ concentration. $\mathrm{CO}_{2}$ fluxes from the ocean as well as anthropogenic emissions of $\mathrm{CO}_{2}$ were used to calculate the atmospheric concentration.

In this experiment, the $\mathrm{CO}_{2}$ concentration reaches $2103 \mathrm{ppm}$ around the year 2450 (Fig. 10a). This is substantially higher than the maximum for the experiment in which the terrestrial biosphere acts on the biogeochemistry. Due to the uptake of $\mathrm{CO}_{2}$, the terrestrial biosphere reduces the maximum $\mathrm{CO}_{2}$ concentration in the atmosphere with more than $400 \mathrm{ppm}$. This reduction of the $\mathrm{CO}_{2}$ concentration is accompanied by a slight decrease of the global mean temperature (Fig. 10b), which is slightly above $0.5 \mathrm{~K}$ when the $\mathrm{CO}_{2}$ concentration is largest. Till the end of the experiment, the difference is slightly reduced ( $350 \mathrm{ppm} \mathrm{CO}_{2}$ and $0.39 \mathrm{~K}$, both averaged for 2801-3000), due to an increasing uptake of carbon by the ocean, caused by the higher $\mathrm{CO}_{2}$ concentration.

In summary, the biogeophysical feedbacks from the terrestrial biosphere cause an amplification, and the biogeochemical feedbacks cause a reduction of the changes in climate. The biogeophysical feedbacks cause an additional warming of $0.26 \mathrm{~K}$ averaged for 28013000 (A2), with largest effects at high latitudes of the northern

(a)
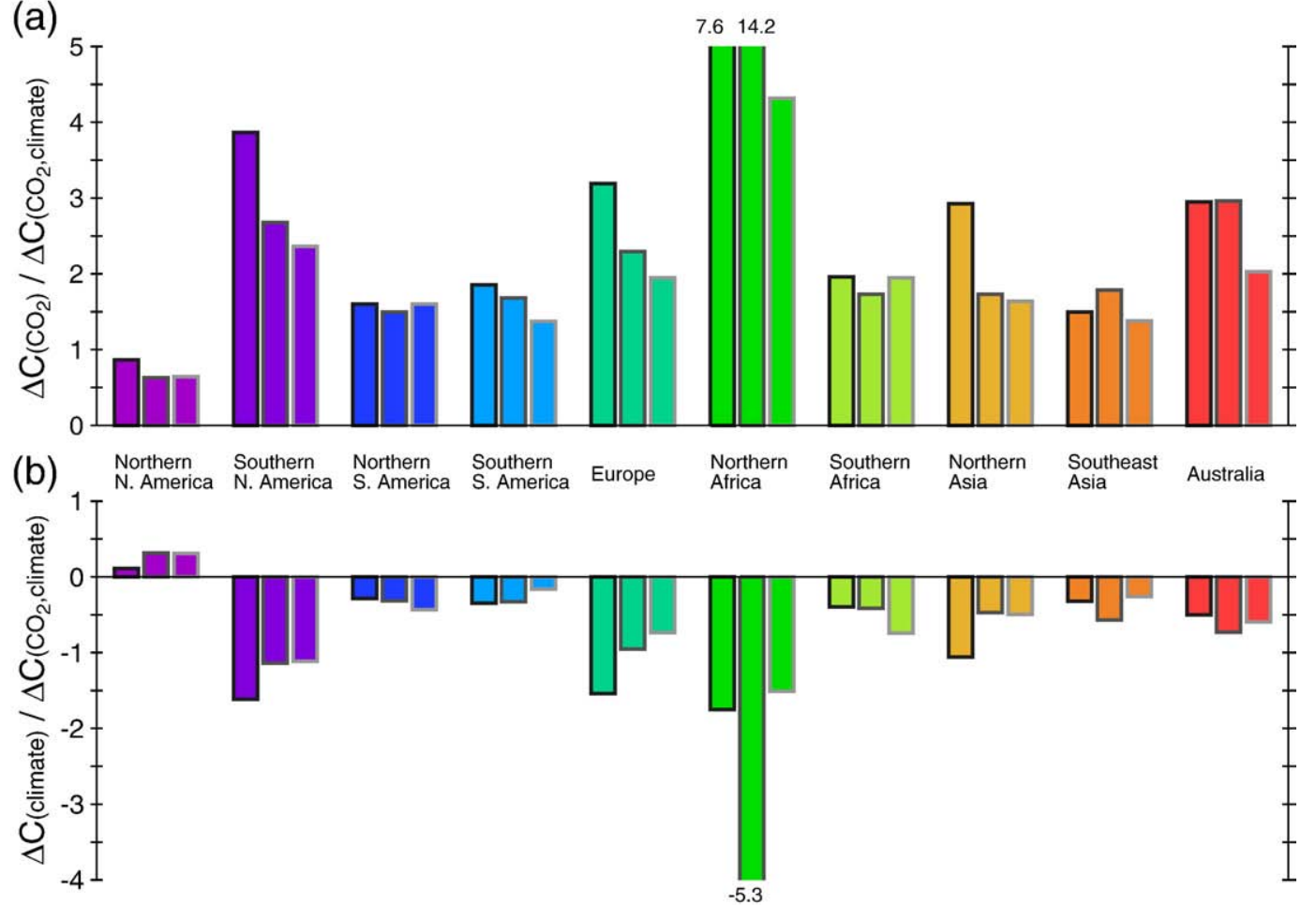

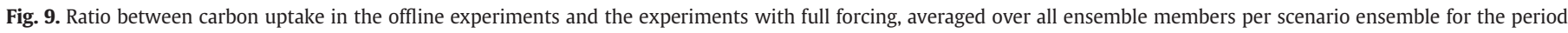

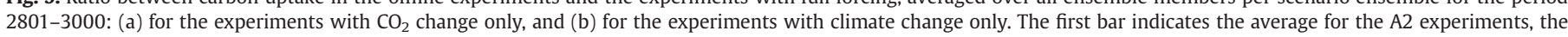
second bar for the A1B experiments and the third bar for the B1 experiments. The regions are defined as in Fig. 8 . 
(a)

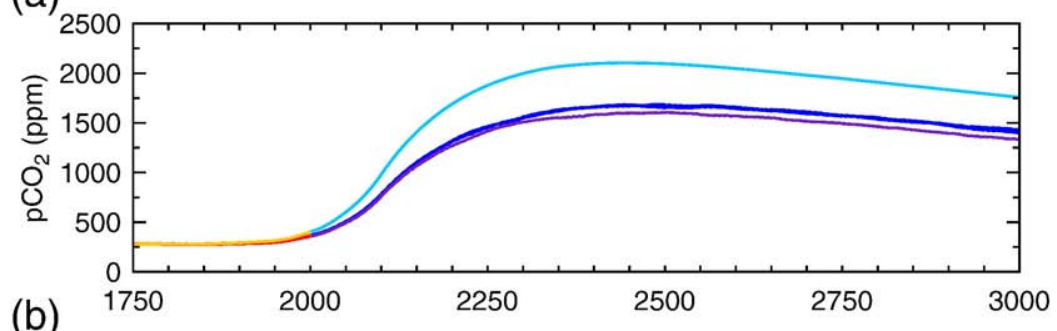

(b)

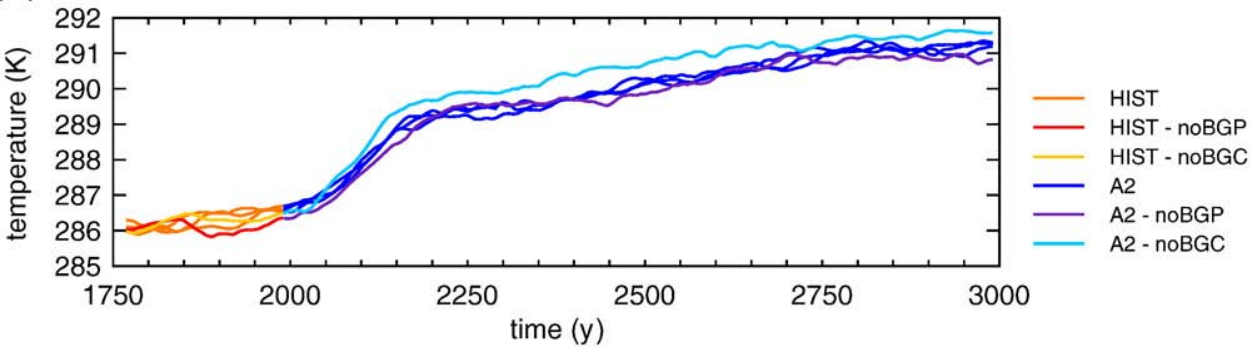

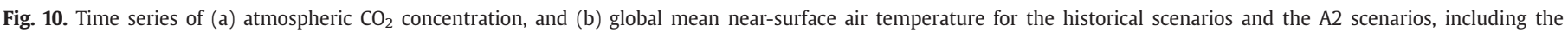
experiments in which the biogeophysical effects or the biogeochemical effects of the terrestrial biosphere were removed (-noBGP and -noBGC, respectively).

\section{(a)}

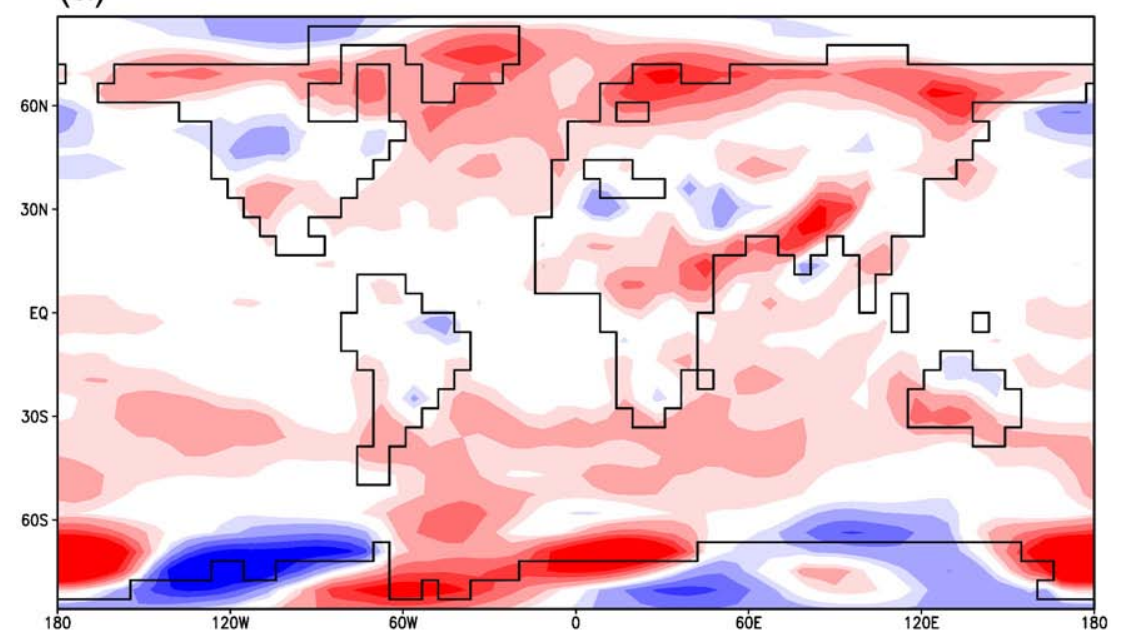

(b)

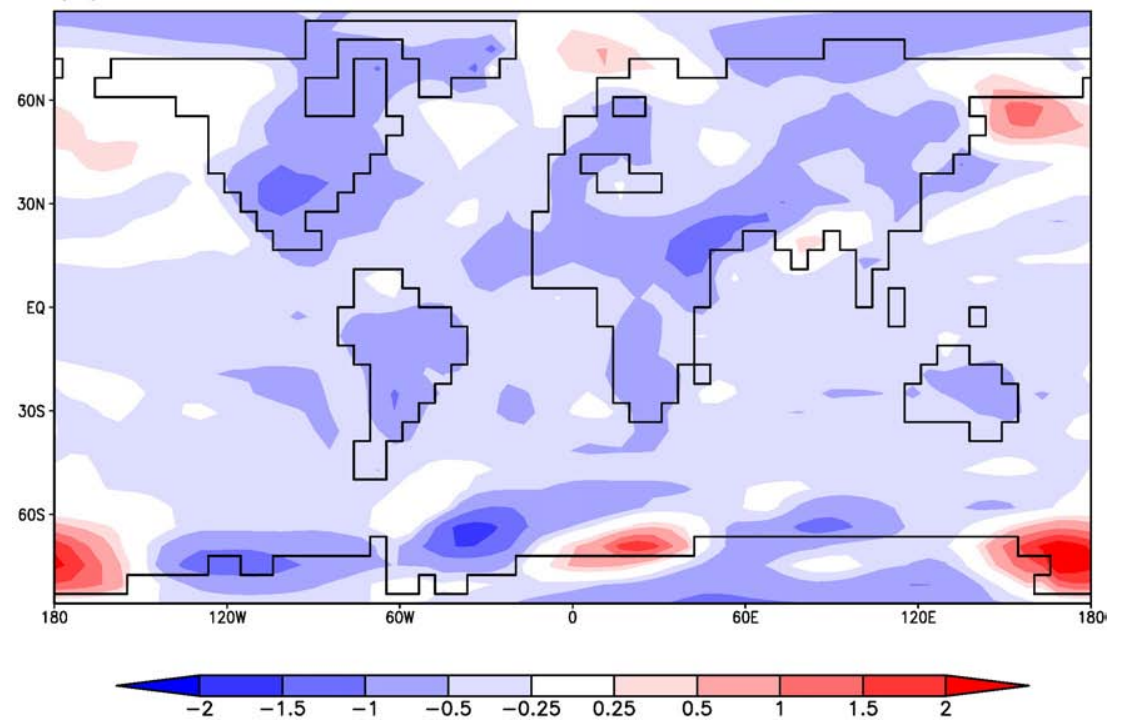

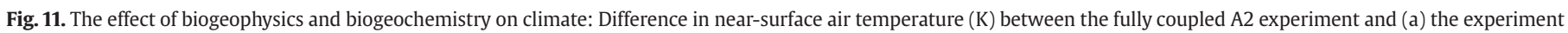
without biogeophysics (A2-noBGP), or (b) the experiment without biogeochemistry (A2-noBGC), averaged for years 2801-3000. 
hemisphere. Due to the pronounced changes in albedo, local increase in temperature can reach up to $2 \mathrm{~K}$ here (Fig. 11a). The biogeochemical feedbacks cause a global cooling of $0.39 \mathrm{~K}$ averaged for 2801-3000 (A2), caused by a decrease of the atmospheric $\mathrm{CO}_{2}$ concentration with $400 \mathrm{ppm}$. The pattern of cooling (Fig. 11b) matches well with the general warming pattern caused by the enhanced $\mathrm{CO}_{2}$ concentration.

\section{Discussion}

The changes in the biogeography and biogeochemistry of the terrestrial biosphere, and thereby their feedbacks to the climate system, depend greatly on the representation of the main processes in the vegetation model LPJ. Major processes with regard to these feedbacks include the photosynthesis response to elevated $\mathrm{CO}_{2}$ concentrations and the sensitivity of respiration to temperature.

Although laboratory experiments have shown a clear increase of photosynthesis with enhanced $\mathrm{CO}_{2}$ levels, field experiments seem to produce a less pronounced effect (e.g. Ainsworth and Long, 2005). Both the effect of increased $\mathrm{CO}_{2}$ concentration on photosynthesis and the effect of temperature changes on respiration in LPJ are relatively large compared to other models (Cramer et al., 2001). The effects of $\mathrm{CO}_{2}$ concentrations as high as reached in the experiments shown here, especially in the A2 experiments, are poorly researched, and are very uncertain. Cao and Woodward (1998) predict a saturation of NPP at $1200 \mathrm{ppm} \mathrm{CO}_{2}$. Soil formation processes other than carbon accumulation are not taken into account, and soil properties are not considered as a burden for plant dispersal.

Land use is not taken into account for this study, although the natural vegetation has been changed by man in substantial parts of the world, and changes in land use might be important for the future. On the other hand, predicting changes in land use for 1000 years ahead would have been uncertain as well. The exponential decrease of the emissions of $\mathrm{CO}_{2}$ as assumed after 2100 is an artificial measure to stabilize the atmospheric $\mathrm{CO}_{2}$ concentrations on the longer timescales, enabling to study relevant feedbacks on these timescales. In the light of these limitations, this study should be merely considered as a sensitivity study to elevated $\mathrm{CO}_{2}$ concentrations rather than as a prediction for the next 1000 years.

The increase in $\mathrm{CO}_{2}$ concentration causes an increase in terrestrial carbon storage due to $\mathrm{CO}_{2}$ fertilization. Climate change reduces this increase, mainly through rising temperatures, which cause a decrease in turnover time of litter and soil carbon. Similar effects were obtained by Friedlingstein et al. (2003) and Govindasamy et al. (2005). Cox et al. (2000) simulated an even stronger decrease of carbon storage due to climate change for the IS92a scenario, exceeding the increase in carbon storage due to $\mathrm{CO}_{2}$ fertilization. Although the general trend, especially in atmospheric $\mathrm{CO}_{2}$ concentration, is rather similar between our experiments and the $\mathrm{A} 1 \mathrm{~B}$ and $\mathrm{A} 2$ experiments performed by Friedlingstein et al. (2003), Govindasamy et al. (2005) and Fung et al. (2005), the distribution of carbon uptake between terrestrial biosphere and ocean differs greatly. Whereas carbon storage in the A2 experiment of Govindasamy et al. (2005) takes place mainly in the terrestrial biosphere ( $47 \%$ of the emissions by 2100 , and $10 \%$ for the oceans), the other studies, as our study, have a more equal distribution of carbon over land and ocean. The land surface takes up 22\% (Dufresne et al., 2002; Friedlingstein et al., 2003), 25\% (Fung et al., 2005 ), and $20 \%$ (this study) by 2100 , the oceans take up $31 \%$ (Dufresne et al., 2002; Friedlingstein et al., 2003), 21\% (Fung et al., 2005), and 21\% (this study) by 2100. Large differences between the models rise from the sensitivity of the modelled climate to changes in the atmospheric $\mathrm{CO}_{2}$ concentration. Although the studies mentioned before have roughly similar atmospheric $\mathrm{CO}_{2}$ concentrations, the climate effects differ substantially. Warming for the A2 scenarios by 2100 obtained in the other studies is $3.0 \mathrm{~K}$ (Dufresne et al., 2002, 1860-2100) and $3.2 \mathrm{~K}$ (Govindasamy et al., 2005, 1900-2100), compared to $1.8 \mathrm{~K}$ (Fung et al., $2005,1820-2100)$ and $1.6 \mathrm{~K}(1750-2100)$ in our A2 experiment.
The interactions between land and atmosphere are complex, partly because the biogeophysical and biogeochemical effects shown above cause secondary effects, e.g. alteration of carbon storage caused by climate-related land surface changes, which in turn changes climate. The overall biogeophysical effect of the terrestrial biosphere on climate change is ambiguous. On the one hand, positive feedbacks between temperature, albedo, and forest growth, as were shown in Fig. 6, cause an essentially local amplification of the temperature change caused by the rising $\mathrm{CO}_{2}$ concentration. On the other hand, forest growth itself reduces this $\mathrm{CO}_{2}$ concentration due to uptake of carbon, thereby causing an overall negative feedback on global temperature. Besides these two processes, the effect of temperature rise on carbon storage at high latitudes is ambiguous itself, as it is the result of two counteracting mechanisms: it will increase forest growth, but it will accelerate carbon decay in soils as well.

Betts (2000) suggested that the biogeophysical effect (i.e. albedo change) of afforestation at high latitudes is larger than the biogeochemical effect due to afforestation (i.e. temperature reduction due to reduction of atmospheric $\mathrm{CO}_{2}$ concentration related to the uptake of carbon), for present-day circumstances. Claussen et al. (2001) compared biogeophysical and biogeochemical feedbacks for tropical and boreal forests under present-day conditions, and found that the biogeochemical feedback is more important for the tropical forests, whereas the biogeophysical feedback is more important for the boreal forests. Note that the experiments differ widely in setup from each other and from the experiments we performed here. In our experiments with high $\mathrm{CO}_{2}$ emissions, the cooling due to carbon storage of $0.39 \mathrm{~K}$ for $2801-3000$ is larger than the warming of $0.26 \mathrm{~K}$ from the biogeophysical interactions, but for certain regions at high latitudes the biogeophysical effect could be larger than the biogeochemical effect.

The experiments without and with biogeophysical effects (A2 and A2-noBGP) show a slight difference in atmospheric $\mathrm{CO}_{2}$ concentration (Fig. 10a): the biogeophysical effects lead to a decrease of terrestrial carbon storage and an increase of the atmospheric $\mathrm{CO}_{2}$ concentration. This decrease in terrestrial carbon storage mainly takes place in the areas which become warmer due to interactive land surface changes (Fig. 6c), where turnover rates of carbon in vegetation and soils increase additionally.

\section{Conclusions}

The effects of biogeophysical and biogeochemical interactions between vegetation and climate were studied with a complex earth system model. For the period 1750-2000, the model simulations of atmospheric $\mathrm{CO}_{2}$ concentration agree reasonably well with the observations from ice cores and direct air samples.

Shifts in vegetation were predicted for the northern hemisphere high latitudes, where bare soil was replaced by herbs and boreal trees, and the border between temperate and boreal forest moved northward. Furthermore, temperate forests in the southern hemisphere (South America, southern Africa) were replaced by tropical forests. The largest biogeophysical feedback from these changes in vegetation distribution occurs at high latitudes, where land albedo was reduced up to 0.25 . The positive feedback between temperature, forest growth and albedo results in a local warming up to $2 \mathrm{~K}$ for the period 28013000 in the A2 scenario compared to a similar experiment without land surface changes, or $0.26 \mathrm{~K}$ on global average. This change is relatively small compared to the $4.9 \mathrm{~K}$ global increase in surface air temperature, with an even stronger warming over land.

$\mathrm{CO}_{2}$ fertilization caused the terrestrial carbon storage to rise substantially. This effect is partly counterbalanced by climate change, which is mainly due to a faster turnover of litter and soil carbon caused by higher temperatures at high latitudes.

The uptake of $\mathrm{CO}_{2}$ by the terrestrial biosphere has lead to a decrease of the atmospheric $\mathrm{CO}_{2}$ concentration of $350 \mathrm{ppm}$ for the $\mathrm{A} 2$ 
experiment for 2801-3000, which resulted in a cooling of $0.39 \mathrm{~K}$. The negative biogeochemical feedback on climate change and terrestrial carbon storage is thus larger than the positive biogeophysical feedback on a global scale for these long-term future climate change scenarios. Overall, the terrestrial biosphere is simulated to be a net dampening factor of climate change on timescales of the order of centuries to millennia. However, on a local scale the changes of the land surface might become more important, most likely at high latitudes of the northern hemisphere. Both biogeochemical and biogeophysical changes are approximately one order of magnitude smaller than the direct effect of $\mathrm{CO}_{2}$ increase on climate, but their effects are nevertheless substantial.

\section{Acknowledgements}

This study was performed in the CLIMCYC project, funded by the DEKLIM program of the German Ministry of Education and Research (BMBF). The simulations were performed at the German Climate Computing Centre (DKRZ). Comments from Thomas Raddatz, Dominique Bachelet, David Price and two anonymous reviewers helped to improve the manuscript substantially.

\section{References}

Ainsworth, E., Long, S., 2005. What have we learned from 15 years of free-air $\mathrm{CO}_{2}$ enrichment (FACE)? A meta-analytic review of the responses of photosynthesis, canopy properties and plant production to rising $\mathrm{CO}_{2}$. New Phytologist $165,351-371$.

Arakawa, A., Lamb, V., 1977. Computational design of the basic dynamical processes of the UCLA general circulation model. Methods in Computational Physics 17, $173-265$.

Arrhenius, S., 1896. On the influence of carbonic acid in the air upon the temperature of the ground. Philosophical Magazine 41, 237-276.

Betts, R., 2000. Offset of the potential carbon sink from boreal forestation by decreases in surface albedo. Nature 408, 187-190.

Björkström, A., 1979. A model of $\mathrm{CO}_{2}$ interaction between atmosphere, oceans, and land biota. In: Bolin, B., Degens, E., Kempe, S., Ketner, P. (Eds.), The Global Carbon Cycle, SCOPE 13. John Wiley.

Bonan, G., Pollard, D., Thompson, S., 1992. Effects of boreal forest vegetation on global climate. Nature 359, 716-718.

Brovkin, V., Ganopolski, A., Svirezhev, Y., 1997. A continuous climate-vegetation classification for use in climate-biosphere studies. Ecological Modelling 101, 251-261.

Brovkin, V., Levis, S., Loutre, M.-F., Crucifix, M., Claussen, M., Ganopol-sky, A., Kubatzki, C., Petoukhov, V., 2003. Stability analysis of the climate-vegetation system in the northern high latitudes. Climatic Change 57, 119-138.

Cao, M., Woodward, F., 1998. Dynamic responses of terrestrial ecosystem carbon cycling to global climate change. Nature 393, 249-252.

Charney, J., 1975. Dynamics of deserts and droughts in the Sahel. Quarterly Journal of the Royal Meteorological Society 101 (428), 193-202.

Claussen, M., Brovkin, V., Ganopolski, A., 2001. Biogeophysical versus bio-geochemical feedbacks of large-scale land cover change. Geophysical Research Letters 28 (6), 1011-1014.

Claussen, M., Brovkin, V., Ganopolski, A., Kubatzki, C., Petoukhov, V., 2003. Climate change in Northern Africa: the past is not the future. Climatic Change 57 (1-2), 99-118.

Cox, Betts, P.R., Jones, C., Spall, S., Totterdell, I., 2000. Acceleration of global warming due to carbon-cycle feedbacks in a coupled climate model. Nature 408, 184-187.

Cramer, W., Bondeau, A., Woodward, F., I.C., P., Betts, R., Brovkin, V., Cox, P., Fisher, V., Foley, J., Friend, A., Kucharik, C., Lomas, M., Ra-mankutty, N., Sitch, S., Smith, B. White, A., Young-Molling, C., 2001. Global response of terrestrial ecosystem structure and function to $\mathrm{CO}_{2}$ and climate change: results from six dynamic global vegetation models. Global Change Biology 7, 357-373.

Dickinson, R., Henderson-Sellers, A., 1988. Modelling tropical deforestation: a study of GCM land-surface parameterizations. Quarterly Journal of the Royal Meteorological Society $114,439-462$

Douville, H., Royer, J.-F., 1997. Influence of the temperate and boreal forests on the northern hemisphere climate in the Météo-France climate model. Climate Dynamics 13, 57-74.

Dufresne, J.-L., Friedlingstein, P., Berthelot, M., Bopp, L., Ciais, P., Fair-head, L., Le Treut, H., Monfray, P., 2002. On the magnitude of positive feedback between future climate change and the carbon cycle. Geophysical Research Letters 29. doi:10.1029/2001GL013777.

Foley, J., Prentice, I., Ramankutty, N., Levis, S., Pollard, D., Sitch, S., Hax-eltine, A., 1996. An integrated biosphere model of land surface processes, terrestrial carbon balance, and vegetation dynamics. Global Biogeochemical Cycles 10 (4), 603-628.

Friedli, H., Lötscher, H., Oeschger, H., Siegenthaler, U., Stauffer, B., 1986. Ice core record of the ${ }^{13} \mathrm{C} /{ }^{12} \mathrm{C}$ ratio of atmospheric $\mathrm{CO}_{2}$ in the past two centuries. Nature 324 237-238

Friedlingstein, P., Bopp, L., Ciais, P., Dufresne, J.-L., Fairhead, L., LeTreut, H., Monfray, P. Orr, J., 2001. Positive feedback between future climate change and the carbon cycle. Geophysical Research Letters 28 (8), 1543-1546.
Friedlingstein, P., Cox, P., Betts, R., Bopp, L., Von Bloh, W., Brovkin, V., Cadule, P., Doney, S., Eby, M., Fung, I., Bala, G., John, J., Jones, C., Joos, F., Kato, T., Kawamiya, M., Knorr, W., Lindsay, K., Matthews, H., Raddatz, T., Rayner, P., Reick, C., Roeckner, E., Schnitzler, K.-G., Schnur, R., Strassmann, K., Weaver, A., Yoshikawa, C., Zeng, N., 2006. Climatecarbon cycle feedback analysis, results from the $C^{4} \mathrm{MIP}$ model intercomparison. Journal of Climate 19 (14), 3337-3353. doi:10.1175/JCLI3800.1.

Friedlingstein, P., Dufresne, J.-L., Cox, P., Rayner, P., 2003. How positive is the feedback between climate change and carbon? Tellus 55B, 692-700.

Fung, I., Doney, S., Lindsay, K., John, J., 2005. Evolution of carbon sinks in a changing climate. Proceedings of the National Academy of Sciences 102 (32), 11201-11206.

Goudriaan, J., Ketner, P., 1984. A simulation study for the global carbon cycle, including man's impact on the biosphere. Climatic Change 6, 167-192.

Govindasamy, B., Thompson, S., Mirin, A., Wickett, M., Caldeira, K., 2005. Increase of carbon cycle feedback with climate sensitivity: results from a coupled climate and carbon cycle model. Tellus 57B, 153-163.

Greve, R., 1997. Application of a polythermal three-dimensional ice sheet model to the Greenland ice sheet: response to steady-state and transient climate scenarios. Journal of Climate 10 (5), 901-918.

Houghton, J., Ding, Y., Griggs, D., Noguer, M., Van der Linden, P., Dai, X., Maskell, K., Johnson, C., 2001. Climate Change 2001: The Scientific Basis. Contribution of Working Group I to the Third Assessment Report of the IPCC. Cambridge University Press, Cambridge, United Kingdom.

Houghton, R., Hackler, J., 2002. Carbon flux to the atmosphere from land-use changes. In: Trends: A Compendium of Data on Global Change. Carbon Dioxide Information Analysis Center, Oak Ridge National Laboratory, U.S. Department of Energy, Oak Ridge, USA.

Joos, F., Prentice, I., Sitch, S., Meyer, R., Hooss, G., Plattner, G.-K., Ger-ber, S., Hasselmann, K., 2001. Global warming feedbacks on terrestrial carbon uptake under the Intergovernmental Panel on Climate Change (IPCC) emission scenarios. Global Biogeochemical Cycles 15 (4), 891-907.

Keeling, C., 1960. The concentration and isotopic abundance of carbon dioxide in the atmosphere. Tellus 12, 200-203.

Lunt, D., de Noblet-Ducoudré, N., Charbit, S., 2004. Effects of a melted Greenland ice sheet on climate, vegetation, and the cryosphere. Climate Dynamics 23, 679-694. doi:10.1007/s00382-004-0463-4.

Maier-Reimer, E., 1993. Geochemical cycles in an ocean general circulation model. Preindustrial tracer distributions. Global Biogeochemical Cycles 7 (3), 645-677.

Marland, G., Boden, T., Andres, R., 2005. Global, regional, and national fossil fuel $\mathrm{CO}_{2}$ emissions. In: Trends: A Compendium of Data on Global Change. Carbon Dioxide Information Analysis Center, Oak Ridge National Laboratory, U.S. Department of Energy, Oak Ridge, USA.

Mikolajewicz, U., Voss, R., 2000. The role of the individual air-sea flux components in $\mathrm{CO}_{2}$ induced changes of the ocean's circulation and climate. Climate Dynamics 16, $627-642$

Mikolajewicz, U., Gröger, M., Maier-Reimer, E., Schurgers, G., Vizcaíno, M., Winguth, A., 2007. Long-term effects of anthropogenic $\mathrm{CO}_{2}$ emissions simulated with a complex earth system model. Climate Dynamics 28 (6), 599-633. doi:10.1007/s00382-006-0204-y.

Nakićenović, N., Alcamo, J., Davis, G., De Vries, B., Fenhann, J., Gaffin, S., Gregory, K., Grübler, A., Jung, T., Kram, T., Lebre La Rovere, E., Michaelis, L., Mori, S., Morita, T., Pepper, W., Pitcher, H., Price, L., Riahi, K., Roehrl, A., Rogner, H.-H., Sankovski, A., Schlesinger, M., Shukla, P., Smith, S., Swart, R., Van Rooijen, S., Victor, N., Dadi, Z., 2000. Special report on emissions scenarios. A Special Report of Working Group III of the Intergovernmental Panel on Climate Change. Cambridge University Press, Cambridge, United Kingdom.

Otterman, J., Chou, M.-D., Arking, A., 1984. Effects of nontropical forest cover on climate. Journal of Climate and Applied Meteorology 23, 762-767.

Petoukhov, V. Claussen, M., Berger, A., Crucifix, M., Eby, M., Eliseev, A., Fichefet, T. Ganopolski, A., Goosse, H., Kamenkovich, I., Mokhov, I., Montoya, M., Mysak, L., Sokolov, A., Stone, P., Wang, Z., Weaver, A., 2005. EMIC Intercomparison Project $\left(\right.$ EMIP- $\left.\mathrm{CO}_{2}\right)$ : comparative analysis of EMIC simulations of climate, and of equilibrium and transient responses to atmospheric $\mathrm{CO}_{2}$ doubling. Climate Dynamics 25, 363-385. doi:10.1007/s00382-005-0042-3.

Sausen, R., Voss, R., 1996. Techniques for asynchronous and periodically synchronous coupling of atmosphere and ocean models. Part I: general strategy and application to the cyclo-stationary case. Climate Dynamics 12, 313-323.

Schurgers, G., Mikolajewicz, U., Gröger, M., Maier-Reimer, E., Vizcaíno, M., Winguth, A., 2007. The effect of land surface changes on eemian climate. Climate Dynamics 29 (4), 357-373. doi:10.1007/s00382-007-0237-x.

Shukla, J., Nobre, C., Sellers, P., 1990. Amazon deforestation and climate change. Science 247, 1322-1325.

Sitch, S., Smith, B., Prentice, I., Arneth, A., Bondeau, A., Cramer, W., Kaplan, J., Levis, S., Lucht, W., Sykes, M., Thonicke, K., Venevsky, S., 2003. Evaluation of ecosystem dynamics, plant geography and terrestrial carbon cycling in the LPJ Dynamic Global Vegetation Model. Global Change Biology 9 (2), 161-185.

Thomas, G., Rowntree, P., 1992. The boreal forests and climate. Quarterly Journal of the Royal Meteorological Society 118, 469-497.

Voss, R., Mikolajewicz, U., 2001. Long-term climate changes due to increased $\mathrm{CO}_{2}$ concentration in the coupled atmosphere-ocean general circulation model ECHAM3/ LSG. Climate Dynamics 17, 45-60.

Wang, G., Eltahir, E., 2000. Biosphere-atmosphere interactions over West Africa II: multiple climate equilibria. Quarterly Journal of the Royal Meteorological Society $126,1261-1280$.

Winguth, A., Mikolajewicz, U., Gröger, M., Maier-Reimer, E., Schurgers, G., Vizcaíno, M., 2005. $\mathrm{CO}_{2}$ uptake of the marine biosphere: feedbacks between the carbon cycle and climate change using a dynamic earth system model. Geophysical Research Letters 32. doi:10.1029/2005GL023681. 